\title{
Military Sexual Trauma Among Homeless Veterans
}

\author{
Joanne Pavao, $M P H^{1,2}$, Jessica A. Turchik, PhD ${ }^{1,3}$, Jenny K. Hyun, PhD, MPH', \\ Julie Karpenko, MSW', ${ }^{1,2}$ Meghan Saweikis, $\mathrm{MS}^{1,2}$, Susan McCutcheon, EdD, RN², \\ Vincent Kane, MSS ${ }^{4}$, and Rachel Kimerling, $\mathrm{PhD}^{1,2,5}$
}

\begin{abstract}
'National Center for Posttraumatic Stress Disorder, VA Palo Alto Health Care System, Menlo Park, CA, USA; ${ }^{2}$ Department of Veterans Affairs, Mental Health Services, Washington, DC, USA; ${ }^{3}$ Department of Psychiatry and Behavioral Sciences, Stanford University School of Medicine, Stanford, CA, USA; ${ }^{4}$ Department of Veterans Affairs, National Center on Homelessness Among Veterans, Philadelphia, PA, USA; ${ }^{5}$ Center for Health Care Evaluation, VA Palo Alto Health Care System, Palo Alto, CA, USA.
\end{abstract}

BACKGROUND: Military sexual trauma (MST) is the Veteran Health Administration's (VHA) term for sexual assault and/or sexual harassment that occurs during military service. The experience of MST is associated with a variety of mental health conditions. Preliminary research suggests that MST may be associated with homelessness among female Veterans, although to date MST has not been examined in a national study of both female and male homeless Veterans.

OBJECTIVE: To estimate the prevalence of MST, examine the association between MST and mental health conditions, and describe mental health utilization among homeless women and men.

DESIGN AND PARTICIPANTS: National, cross-sectional study of 126,598 homeless Veterans who used VHA outpatient care in fiscal year 2010.

MAIN MEASURES: All variables were obtained from VHA administrative databases, including MST screening status, ICD-9-CM codes to determine mental health diagnoses, and VHA utilization.

KEY RESULTS: Of homeless Veterans in VHA, $39.7 \%$ of females and $3.3 \%$ of males experienced MST. Homeless Veterans who experienced MST demonstrated a significantly higher likelihood of almost all mental health conditions examined as compared to other homeless women and men, including depression, posttraumatic stress disorder, other anxiety disorders, substance use disorders, bipolar disorders, personality disorders, suicide, and, among men only, schizophrenia and psychotic disorders. Nearly all homeless Veterans had at least one mental health visit and Veterans who experienced MST utilized significantly more mental health visits compared to Veterans who did not experience MST.

CONCLUSIONS: A substantial proportion of homeless Veterans using VHA services have experienced MST, and those who experienced MST had increased odds of mental health diagnoses. Homeless Veterans who had experienced MST had higher intensity of mental health care utilization and high rates of MST-related mental health care. This study highlights the importance of trauma-informed care among homeless Veterans and the success of VHA homeless programs in improving access to mental health care among homeless Veterans.

KEY WORDS: Veterans; homelessness; sexual assault; mental health.
J Gen Intern Med 28(Suppl 2):S536-41

DOI: $10.1007 / \mathrm{s} 11606-013-2341-4$

(C) Society of General Internal Medicine 2013

$\mathrm{M}$ ilitary sexual trauma (MST) is the Veteran Health Administration's (VHA) term for sexual assault and/ or severe and threatening sexual harassment that occurred during military service (U.S. Code, Title 38, §1720D). Among Veterans in VHA care, approximately $22 \%$ of women and $1 \%$ of men report MST. ${ }^{1}$ MST is associated with a wide range of mental health conditions, such as depressive disorders, posttraumatic stress disorder (PTSD), anxiety disorders, substance use disorders (SUD), and adjustment disorders. ${ }^{1,2}$ VHA has established comprehensive policies to address MST, which include universal screening of all VHA patients for MST and providing free care for physical and mental health conditions related to MST. Preliminary research suggests that experiences of MST may be disproportionately common among homeless women Veterans. $^{3-5}$ MST, and associated mental health conditions and functional impairment, has been posited as a military-related risk factor for homelessness among Veterans. ${ }^{6}$ Understanding and addressing the need for MSTrelated mental health care is important in helping VHA meet the needs of both female and male homeless Veterans.

Little is known about the prevalence of MST among homeless Veterans, but emerging evidence suggests a high prevalence of MST among women Veterans who are homeless. In a study of 33 homeless and 165 age-matched housed women Veterans, $53.3 \%$ of homeless women reported sexual assault during military service, a prevalence significantly higher than the $26.8 \%$ among housed women. $^{4}$ Additionally, in a sample of female and male homeless Veterans in VHA SUD residential treatment programs, Benda et al. found that $41.0 \%$ of women and $1.6 \%$ of men reported military sexual abuse. ${ }^{5}$ These findings are consistent with the broader literature, which indicates that rates of lifetime sexual trauma are higher among homeless persons than those who are not home- 
less. ${ }^{7,8}$ These findings also suggest that the prevalence of MST among homeless Veterans in VHA may be substantially higher than the prevalence among all VHA users.

Homeless Veterans who report MST likely experience a significant mental health burden, beyond even the high rates of mental health conditions known to exist among homeless individuals. $^{9-11}$ Few studies have examined the nature and extent of mental health conditions among homeless Veterans who report MST. In a sample of homeless civilian women, those who experienced rape in the past year were more likely to report depression, psychological distress, and lifetime substance abuse compared to homeless women without rape experiences in the past year. ${ }^{12}$ Identifying and treating the mental health conditions associated with trauma, especially MST, may be important for long-term mental health outcomes. Among Benda's sample of homeless women Veterans, those who reported military sexual abuse were significantly more likely to be re-hospitalized in the 3 years following their discharge from a VHA SUD treatment program when compared to women who did not report military sexual abuse. ${ }^{5}$ Given that both sexual trauma and homelessness are associated with increased rates of mental health problems among Veterans, ${ }^{1,9,10}$ examining mental health conditions and mental health service utilization associated with MST among homeless Veterans could inform efforts to address the mental health needs of these Veterans.

Understanding the mental health needs of homeless Veterans who experienced MST is of particular concern given the federal goal of ending homelessness among Veterans by 2015 . These Veterans may benefit from a trauma-informed approach to mental health treatment. ${ }^{13}$ Furthermore, few studies have examined MST among both women and men homeless Veterans, which can help elucidate gender-specific mental health needs in this population. The specific goals of the current research are to: 1) Estimate the proportion of female and male homeless Veterans who have experienced MST; 2) Examine the association between MST and mental health conditions among homeless female and male Veterans; and 3) Describe mental health utilization among homeless women and men, and utilization of MST-related mental health care among those who report MST.

\section{METHODS}

\section{Overview of Study Design and Data Sources}

This is a cross-sectional, national study of homeless Veterans who used VHA care between October 1, 2009 and September 30, 2010. Several VHA administrative data sets were used to obtain variables for the study. Data on homeless status came from the VHA Support Service Center (VSSC) Homeless Registry. The Homeless Registry integrates data from VA healthcare, benefits, and homeless program evaluations and identifies homeless VHA users by: Veterans who accessed a VA homeless service or at-risk program, informed a VA provider of their homelessness status, or placed a claim for emergency housing services. Demographic, diagnostic, and utilization data came from the National Patient Care Database (NPCD), which is the VA's administrative database of all outpatient health care visits. Veterans of Operations Enduring Freedom, Iraqi Freedom, and New Dawn (OEF/OIF/OND) were identified using the VSSC OEF/OIF/OND Roster dated September 2011. MST status was obtained using the VHA MST Support Team Data Archive, which aggregates national MST screening data from 2002 to the present. ${ }^{1,2}$ This study was approved by the Stanford University Institutional Review Board. Of the 131,396 homeless Veterans identified, 126,598 (96.3\%) had an MST screen and were included in the study.

\section{Key Variables}

Since 2002, VHA has used a clinical reminder in the electronic medical record to screen all Veterans seen in VHA outpatient care for MST. The one-time screen prompts clinicians to ask the following questions: "While you were in the military... 1) Did you ever receive uninvited or unwanted sexual attention, such as touching, cornering, pressure for sexual favors, or verbal remarks?; 2) Did someone ever use force or the threat of force to have sex against your will?" VHA codes patients as positive for MST if they respond affirmatively to either screening item.

We used the Agency for Health Research and Quality's Clinical Classifications Software framework for mental health diagnoses to map International Classification of Diseases, 9th Edition Clinical Modification (ICD-9-CM) diagnostic codes to conditions. ${ }^{14,15}$ In some cases, we achieved greater specificity by separating diagnostic codes from larger groups (e.g., separating PTSD from the larger anxiety disorders group). Additionally, we combined alcohol-related and substance-related disorders into one category, SUDs. A patient was considered to have a diagnosis if they had at least one instance of an ICD-9-CM code within a category. We report the nine diagnosis categories that had a frequency of at least $10 \%$ among women or men with MST. The analysis of mental health comorbidity included these nine diagnosis categories.

All outpatient visits with a primary or secondary mental health clinic indicator are coded as a mental health visit.

After each VHA outpatient visit with a Veteran that has a positive MST screen, clinical care providers must indicate whether the "visit was related to MST" in the electronic 
medical record. If a visit is indicated as being related to MST, the Veteran is not billed for the services. Mental health visits with the MST indicator were coded as MSTrelated mental health visits.

\section{ANALYSIS}

All analyses were conducted separately by gender. Comparisons between female and male homeless Veterans were made using Chi-square tests. Adjusted logistic regression models were used to examine Veterans' likelihood of having a mental health diagnosis by MST history, while adjusting for age, race, ethnicity and marital status. Due to the high rate of mental health utilization among homeless women and men, we did not compare the likelihood of mental health utilization by MST history. We examined the intensity of mental health utilization (number of mental health visits) by MST history using a generalized estimating equation model with a negative binomial distribution, while adjusting for age, race, ethnicity, and marital status. Incidence rate ratios (IRR) and $95 \%$ CIs are presented for these analyses. Data were analyzed using Statistical Analysis Software (SAS), version 9.2.

\section{RESULTS}

Table 1 displays the demographics of female and male homeless Veterans ( $n=8,915$ and $n=117,683$ respectively). The prevalence of MST among homeless Veterans was $39.7 \%$ among females and $3.3 \%$ among males. Homeless female Veterans were significantly more likely to have experienced MST, to be younger, non-white, and single, have a service connected disability, and to have served in OEF/OIF/OND compared to homeless male Veterans.

Table 2 provides the prevalence of mental health conditions by MST status among female homeless Veterans. Women who experienced MST had on average more mental health conditions compared to homeless women who did not experience MST (2.9 vs. 2.0, $p<0.001)$. Homeless women with a history of MST were more likely to have a diagnosis of depressive disorders, PTSD, SUDs, anxiety disorders, bipolar disorders, personality disorders, or suicide behaviors compared to homeless women who did not have a history of MST.

Table 3 provides the prevalence of mental health conditions by MST status among male homeless Veterans. Homeless men who experienced MST had on average more mental health conditions compared to men who did not experience MST (2.9 vs. 2.0, $p<0.001)$. Homeless men who had a history of MST were more likely to have all of the mental health diagnoses examined, with the exception of adjustment disorders.

Nearly all homeless Veterans received mental health services $(97.9 \%$ of women, and $95.3 \%$ of men). Homeless women who experienced MST had significantly more mental health visits compared to homeless women without a history of MST (median visits 24 vs.9, IRR $=1.51 ; 95 \%$ $\mathrm{CI}=1.44-1.59)$. This mental health care included MSTrelated mental health care for $89.1 \%$ of homeless women who reported MST, and the median number of MST-related mental health visits among these women was nine. Similar to women, homeless men who experienced MST had a significantly greater number of mental health visits compared to homeless men without a history of MST (median visits 27 vs.14, $\mathrm{IRR}=1.40 ; 95 \% \mathrm{CI}=1.34-1.46)$. This mental health care included one or more MST-related mental health visits for $79.8 \%$ of homeless men who reported MST, with a median number of five MST-related mental health visits.

\section{DISCUSSION}

This is the first study to provide the prevalence of MST in a national sample of female and male homeless VHA users. The prevalence of MST among homeless VHA users (39.7\% women, $3.3 \%$ men) was higher than the prevalence of MST among all VHA users (22\% women, $1 \%$ men), and is consistent with previous studies of homeless Veterans. ${ }^{4,5}$ Although homeless female Veterans were more likely to have experienced MST than male homeless Veterans, the total number of homeless Veterans that experienced MST was similar across genders (3,538 women and 3,915 men). Examination of the association between MST and mental health conditions in this population revealed that MST was associated with an increased mental health burden and more severe mental health comorbidity. Results also document that nearly all homeless VHA users received mental health treatment, whereas women and men who report MST received more intensive services than other homeless women and men, commensurate with their greater mental health burden. Of note, this study only included those Veterans whose homelessness had been identified by VHA, and we do not know the extent to which the mental health needs of Veterans whose homeless status is not detected within VHA are being met. Although additional research on access to mental health care among homeless VHA patients is warranted, this is preliminary but promising evidence that homeless women and men have good access to mental health care, and those who experienced MST are indeed receiving more mental health care.

Homeless Veterans who experienced MST demonstrated a significantly higher likelihood of almost all mental health conditions examined as compared to other 
Table 1. Demographics of Female and Male Homeless Veterans*

\begin{tabular}{|c|c|c|c|c|}
\hline \multirow[t]{3}{*}{ Variable } & & \multicolumn{3}{|c|}{ All homeless Veterans } \\
\hline & & \multirow{2}{*}{$\begin{array}{l}\text { Female }(n=8,915) \\
n(\%)\end{array}$} & \multirow{2}{*}{$\begin{array}{l}\text { Male }(n=117,683) \\
n(\%)\end{array}$} & \multirow[t]{2}{*}{$p$ value } \\
\hline & & & & \\
\hline \multirow[t]{2}{*}{ MST status } & & & & $<0.001$ \\
\hline & Positive screen & $3,538(39.7)$ & $3,915(3.3)$ & $<0001$ \\
\hline \multirow{6}{*}{ Age, years } & $<25$ & $197(2.2)$ & $1,041(0.9)$ & 0.001 \\
\hline & $25-34$ & $1,639(18.4)$ & $7,418(6.3)$ & \\
\hline & $35-44$ & $1,788(20.1)$ & $11,634(9.9)$ & \\
\hline & $45-54$ & $3,534(39.6)$ & $43,881(37.3)$ & \\
\hline & $55-64$ & $1,566(17.6)$ & $44,132(37.5)$ & \\
\hline & $\geq 65$ & $191(2.1)$ & $9,577(8.1)$ & \\
\hline Ethnicity & Hian & & $5800 \quad(40)$ & 0.71 \\
\hline \multirow[t]{6}{*}{ Race } & Hispanic & $448(5.0)$ & $5,809(4.9)$ & $<0.001$ \\
\hline & White & $4,009(45.0)$ & $58,532(49.7)$ & \\
\hline & Black & $3,868(43.4)$ & 46,919 (39.9) & \\
\hline & Asian & $42(0.5)$ & $453(0.4)$ & \\
\hline & Other & $291(3.3)$ & $3,459(2.9)$ & \\
\hline & Unknown & $705(7.9)$ & $8,320(7.1)$ & \\
\hline \multirow{5}{*}{ Marital status } & Divorced & $3916(439)$ & $51654(43$ & 0.002 \\
\hline & Single & $3,537(39.7)$ & $45,078(38.3)$ & \\
\hline & Married & $1,073(12.0)$ & $15,835(13.5)$ & \\
\hline & Widowed & $310(3.5)$ & $4,083(3.5)$ & \\
\hline & Unknown & $79(0.9)$ & $1,033(0.9)$ & \\
\hline \multirow[t]{3}{*}{ Service connection } & & & & $<0.001$ \\
\hline & Not service connected & $4,543(51.0)$ & $75,513(64.2)$ & \\
\hline & $0-50 \%$ & $2,436(27.3)$ & $25,652(21.8)$ & \\
\hline OEF/OIF/OND & $50-100 \%$ & $1,890(21.2)$ & $15,341(13.0)$ & $<0.001$ \\
\hline
\end{tabular}

${ }^{*} M S T=$ military sexual trauma, OEF/OIF/OND = Operation Enduring Freedom, Operation Iraqi Freedom, and Operation New Dawn

homeless men and women, including depression, PTSD, other anxiety disorders, SUDs, bipolar disorders, personality disorders, suicide, and, among men, schizophrenia and psychotic disorders. The three most common mental health conditions among both homeless women and men who had a history of MST were depressive disorders, PTSD and SUDs. These results are particularly notable in light of the high prevalence of mental health conditions among homeless Veterans who do not report MST, which is evident in our data and also consistent with prior research. ${ }^{9-11}$ While prior research has suggested that MST may be a risk factor for homelessness among Veterans, ${ }^{6}$ these results suggest that MST is an important mental health treatment issue for this population as well.

The relationship between MST and PTSD among our sample of homeless individuals was especially striking: MST was associated with a six-fold increase in the odds of a PTSD diagnosis among women and nearly four-fold among men. While this is consistent with prior research where PTSD is one of the disorders most strongly related to MST, ${ }^{1,16,17}$ data also indicates that homeless individuals experience exceptionally high rates of traumatic events $^{5,8,11,18}$ and would be expected to show high base rates of PTSD. Sexual trauma is amongst the traumatic events with the highest conditional risk for PTSD, and MST has been found in prior research to be a stronger predictor of PTSD compared to civilian sexual assault. ${ }^{19}$ MST may be a proxy for the experience of interpersonal trauma in general, as research shows that many Veterans who experience MST have also experienced sexual and/or physical abuse outside of the military. ${ }^{20}$ This is consistent with literature demonstrating an increased risk of interpersonal violence among those with prior trauma, ${ }^{21}$ and this may be particularly high among homeless Veterans who may be more vulnerable to revictimization. ${ }^{8,12}$ In light of this, it may be important for providers to assess for recent interpersonal violence experiences among homeless Veterans who experience MST. While our interpretation of these results is limited due to the lack of information about other trauma exposure, these results do suggest that treatment for MST-related PTSD is especially important in this population.

We found one unanticipated result with respect to mental health conditions: prevalence of adjustment disorders was significantly lower among women Veterans who report MST. This finding suggests that stress reactions may be more severe among those with MST, and more likely to meet criteria for PTSD, or that providers are less likely to diagnose adjustment disorders among individuals who meet criteria for PTSD. Little data exists to suggest that MST would be protective against mental health conditions, thus this finding merits further investigation in other samples. 
Table 2. Prevalence of Mental Health Conditions by MST Status Among Female Homeless Veterans*

\begin{tabular}{|c|c|c|c|}
\hline \multirow[t]{2}{*}{$\begin{array}{l}\text { Mental health } \\
\text { condition }\end{array}$} & $\begin{array}{l}\text { Positive } \\
\text { MST } \\
\text { screen } \\
(n=3,538)\end{array}$ & $\begin{array}{l}\text { Negative } \\
\text { MST } \\
\text { screen } \\
(n=5,377)\end{array}$ & \multirow[t]{2}{*}{ AOR (95\% CI) } \\
\hline & $n(\%)$ & $n(\%)$ & \\
\hline $\begin{array}{r}\text { Depressive } \\
\text { disorders }\end{array}$ & $2,581(73.0)$ & $3,210(59.7)$ & $1.78(1.62-1.95)$ \\
\hline $\begin{array}{l}\text { Posttraumatic } \\
\text { stress disorder }\end{array}$ & $2,292(64.8)$ & $1,238(23.0)$ & $6.24(5.68-6.86)$ \\
\hline $\begin{array}{l}\text { Substance use } \\
\text { disorders }\end{array}$ & $1,602(45.3)$ & $1,795(33.4)$ & $1.62(1.49-1.77)$ \\
\hline Anxiety disorders & $1,247(35.2)$ & $1,453(27.0)$ & $1.42(1.29-1.55)$ \\
\hline Bipolar disorders & $795(22.5)$ & $832(15.5)$ & $1.53(1.37-1.70)$ \\
\hline $\begin{array}{l}\text { Adjustment } \\
\text { disorders }\end{array}$ & $594(16.8)$ & $1,060(19.7)$ & $0.84(0.75-0.94)$ \\
\hline $\begin{array}{l}\text { Personality } \\
\text { disorders }\end{array}$ & $583(16.5)$ & $483(9.0)$ & $1.90(1.67-2.16)$ \\
\hline $\begin{array}{l}\text { Schizophrenia } \\
\text { and other } \\
\text { psychotic } \\
\text { disorders }\end{array}$ & $375(10.6)$ & $522(9.7)$ & $1.12(0.97-1.29)$ \\
\hline $\begin{array}{l}\text { Suicide and } \\
\text { intentional self } \\
\text { inflicted injury }\end{array}$ & $274(7.7)$ & $256(4.8)$ & $1.64(1.37-1.95)$ \\
\hline
\end{tabular}

*AOR adjusted for age, race, ethnicity, and marital status $+M S T=$ military sexual trauma, $A O R=$ adjusted odds ratio, $C I=$ confidence interval

Virtually all homeless women and men received mental health services. Women and men who experienced MST received an even greater intensity of mental health services, including MST-related mental health care specifically, commensurate with their higher mental health burden. These findings underscore the emphasis on mental health in VHA homeless services, where homeless case managers focus on housing stability and mental health treatment engagement to assist Veterans in ending their homelessness. The large majority of homeless women and men who reported MST received MST-related mental health care. These data indicate that mental health providers who treat homeless women and men are aware that MST is an important clinical issue in this population and are addressing these experiences during treatment. Homeless Veterans with and without MST appear to have good access to and engagement with mental health services, which is essential to promote the health and functioning of this population.

These data should be interpreted in light of several considerations. The cross-sectional nature of the data does not allow for causal inferences. Further, since the study only included homeless Veterans using VHA care, the results cannot be generalized to the larger population of homeless Veterans who do not use VHA care. While MST may be an important issue for all homeless Veterans, those that have not connected with VHA services may experience additional stressors or conditions that impede access to care that are not reflected in our results. Additionally, this study only includes those Veterans who endorse MST experiences during VHA screening. While the items included in the
Table 3. Prevalence of Mental Health Conditions by MST Status Among Male Homeless Veterans* ${ }^{*}$

\begin{tabular}{|c|c|c|c|}
\hline \multirow[t]{2}{*}{$\begin{array}{l}\text { Mental health } \\
\text { condition }\end{array}$} & \multirow{2}{*}{$\begin{array}{l}\text { Positive } \\
\text { MST } \\
\text { screen } \\
(n=3,915) \\
n(\%)\end{array}$} & \multirow{2}{*}{$\begin{array}{l}\text { Negative } \\
\text { MST screen } \\
(n=113,768)\end{array}$} & \multirow[t]{2}{*}{$\operatorname{AOR}(95 \%$ CI $)$} \\
\hline & & & \\
\hline $\begin{array}{l}\text { Substance use } \\
\text { disorders }\end{array}$ & $2,685(68.6)$ & 70,367 (61.9) & $1.32(1.23-1.41)$ \\
\hline $\begin{array}{l}\text { Depressive } \\
\text { disorders }\end{array}$ & $2,620(66.9)$ & $56,956(50.1)$ & $1.95(1.82-2.09)$ \\
\hline $\begin{array}{l}\text { Posttraumatic } \\
\text { stress disorder }\end{array}$ & $2,009(51.3)$ & 24,904 (21.9) & $3.80(3.56-4.06)$ \\
\hline $\begin{array}{l}\text { Anxiety } \\
\text { disorders }\end{array}$ & $1,131(28.9)$ & $22,529(19.8)$ & $1.57(1.46-1.69)$ \\
\hline $\begin{array}{l}\text { Schizophrenia } \\
\text { and other } \\
\text { psychotic } \\
\text { disorders }\end{array}$ & $706(18.0)$ & 13,477 (11.8) & $1.67(1.54-1.82)$ \\
\hline $\begin{array}{l}\text { Bipolar } \\
\text { disorders }\end{array}$ & 702 (17.9) & 11,687 (10.3) & $1.82(1.67-1.98)$ \\
\hline $\begin{array}{l}\text { Adjustment } \\
\text { disorders }\end{array}$ & $631(16.1)$ & $18,327(16.1)$ & $0.98(0.90-1.07)$ \\
\hline $\begin{array}{l}\text { Personality } \\
\text { disorders }\end{array}$ & $500(12.8)$ & $6,969(6.1)$ & $2.15(1.95-2.37)$ \\
\hline $\begin{array}{l}\text { Suicide and } \\
\text { intentional self } \\
\text { inflicted injury }\end{array}$ & 415 (10.6) & 7,031 (6.2) & $1.73(1.56-1.92)$ \\
\hline
\end{tabular}

*AOR adjusted for age, race, ethnicity, and marital status $\dagger M S T=$ military sexual trauma, $A O R=$ adjusted odds ratio, $C I=$ confidence interval

MST screen have shown high sensitivity and specificity when compared to clinical interview, ${ }^{22}$ and research demonstrates that people are more likely to disclose trauma if asked by a provider, ${ }^{23-26}$ there may be some Veterans who choose not to disclose an MST experience during screening. Though our results indicate that MST is an important focus for VHA mental health care of homeless Veterans, we do not have data for other types of trauma exposure, which may be important foci as well. Similarly, while our results show high rates of engagement with mental health treatment, we do not have data on other psychosocial services, such as supportive housing or employment assistance that are essential for assisting homeless Veterans. A prior study of homeless women Veterans identified several barriers in access to psychosocial services, ${ }^{27}$ and future studies should assess utilization of services other than mental health care, and whether engagement may vary based on MST status and gender. Finally, though our data suggest that most Veterans who report MST are receiving mental health services addressing these experiences, we do not have information about the treatment approaches used by providers in delivering MSTrelated mental health care, nor the treatment outcomes of such approaches.

Overall, this study provides important information about MST, mental health diagnoses and mental health care utilization among homeless Veterans. Services to homeless Veterans are a key priority for VHA, and our data suggest 
that efforts to engage this population in mental health care appear successful. Our results also underscore that MST is an important clinical issue among this population, particularly MST-related PTSD, and that mental health providers appear to be aware of these issues and addressing MST in mental health treatment. The high proportion of Veterans receiving mental health care, and the intensity of those services, is encouraging. Homeless Veterans who have experienced MST received more intensive mental health care, which is appropriate given the higher prevalence of mental health conditions among this subgroup of homeless Veterans. This study highlights the importance of traumainformed approaches to care for this population. It is important that homeless case managers understand how trauma related issues, including MST, may affect a Veteran's ability to obtain and maintain housing, healthy relationships, and employment. For example, a traumainformed case management model was developed in VHA and is widely used within homeless programs to appropriately address the needs of these Veterans. ${ }^{28}$ Traumainformed models of mental health care, such as Seeking Safety, a trauma-informed approach to SUD treatment, have shown promise with homeless female Veterans. ${ }^{11}$ Continued research regarding interpersonal trauma and PTSD among homeless Veterans is important. Future studies focused on mental health outcomes, especially for those impacted by MST and PTSD, could yield important information that would contribute to national efforts to end homelessness among Veterans.

Acknowledgements: This material is the result of work supported with resources and the use of facilities at the National Center for Posttraumatic Stress Disorder, VA Palo Alto Health Care System and the VA Advanced Fellowship Program in Mental Illness Research and Treatment, VA Office of Academic Affiliations. The views expressed in this article are those of the authors and do not necessarily reflect the position or policy of the Department of Veterans Affairs or the United States Government.

Conflict of Interest: The authors declare that they do not have any conflicts of interest. No author has a financial interest or other dual commitment relevant to this manuscript. All authors have contributed sufficiently to the project to be included as authors.

Corresponding Author: Joanne Pavao, MPH; National Center for Posttraumatic Stress Disorder, VA Palo Alto Health Care System, 795 Willow Rd (PTSD-324), Menlo Park, CA 94025, USA (email: Joanne.pavao@va.gov).

\section{REFERENCES}

1. Kimerling R, Gima K, Smith MW, Street AE, Frayne S. The Veterans Health Administration and military sexual trauma. Am J Public Health. 2007;97(12):2160-6.

2. Kimerling R, Street AE, Pavao J, et al. Military-related sexual trauma among Veterans Health Administration patients returning from Afghanistan and Iraq. Am J Public Health. 2010;100(8):1409-12.
3. Hamilton AB, Poza I, Washington DL. Homelessness and trauma go hand-in-hand: pathways to homelessness among women veterans. Womens Health Issues. 2011;21(4, Supplement):S203-9.

4. Washington DL, Yano EM, McGuire J, Hines V, Lee M, Gelberg L. Risk factors for homelessness among women veterans. J Health Care Poor Underserved. 2010;21(1):82-91.

5. Benda B. Survival analyses of social support and trauma among homeless male and female veterans who abuse substances. Am J Orthopsychiatry. 2006;76(1):70-9.

6. Balshem H, Christensen V, Tuepker A, Kansagara D. A critical review of the literature regarding homelessness among veterans: VA-Evidence Based Synthesis Program Project \#05-225; 2011.

7. Kushel MB, Evans JL, Perry S, Robertson MJ, Moss AR. No door to lock: victimization among homeless and marginally housed persons. Arch Intern Med. 2003;163(20):2492-9.

8. Wenzel SL, Koegel P, Gelberg L. Antecedents of physical and sexual victimization among homeless women: a comparison to homeless men. Am J Community Psychol. 2000;28(3):367-90.

9. Adams J, Rosenheck RA, Gee L, Seibyl C, Kushel M. Hospitalized younger: a comparison of a national sample of homeless and housed inpatient veterans. J Health Care Poor Underserved. 2007;18(1): 173-84.

10. O'Toole TP, Conde-Martel A, Gibbon JL, Hanusa BH, Fine MJ. Health care of homeless veterans. J Gen Intern Med. 2003;18(11):929-33.

11. Desai RA, Harpaz-Rotem I, Najavits LM, Rosenheck RA. Impact of the Seeking Safety program on clinical outcomes among homeless female veterans with psychiatric disorders. Psychiatr Serv. 2008;59(9):996-1003.

12. Wenzel SL, Leake BD, Gelberg $\mathbf{L}$. Health of homeless women with recent experience of rape. J Gen Intern Med. 2000;15(4):265-8.

13. Harris $\mathbf{M}$, Fallot $\mathbf{R}$, eds. Using Trauma Theory to Design Service Systems. San Francisco: Jossey-Bass; 2001.

14. Elixhauser A, Steiner C, Palmer L. Clinical Classifications Software (CCS): U.S. Agency for Healthcare Research and Quality; 2008: Available: http://www.hcup-us.ahrq.gov/toolssoftware/ccs/ccs.jsp.

15. National Center for Health Statistics and Centers for Medicare and Medicaid Services. The International Classification of Diseases (9th Rev., Clinical Modification). Washington: Authors; 2008.

16. Suris AM, Lind L, Kashner TM, Borman PD, Petty F. Sexual assault in women veterans: an examination of PTSD risk, health care utilization, and cost of care. Psychosom Med. 2004;66(5):749-56.

17. Street AE, Stafford J, Mahan CM, Hendricks A. Sexual harassment and assault experienced by reservists during military service: prevalence and health correlates. J Rehabil Res Dev. 2008;45(3):409-20.

18. North CS, Smith EM, Spitznagel EL. Violence and the homeless: an epidemiologic study of victimization and aggression. J Trauma Stress. 1994;7(1):95-110.

19. Yaeger D, Himmelfarb N, Cammack A, Mintz J. DSM-IV diagnosed posttraumatic stress disorder in women veterans with and without military sexual trauma. J Gen Intern Med. 2006;21(Suppl 3):S65-9.

20. Sadler AG, Booth BM, Cook BL, Doebbeling BN. Factors associated with women's risk of rape in the military environment. Am J Ind Med. 2003;43(3):262-73.

21. Gidycz CA, Coble CN, Latham L, Layman MJ. Sexual assault experience in adulthood and prior victimization experiences: a prospective analysis. Psychol Women Q. 1993;17:151-68.

22. McIntyre LM, Butterfield MI, Nanda $\mathbf{K}$, et al. Validation of a trauma questionnaire in veteran women. J Gen Intern Med. 1999;14:186-9.

23. Agar K, Read J, Bush J-M. Identification of abuse histories in a community mental health centre. J Ment Heal. 2002;11:533-43.

24. Campbell R, Raja S. The sexual assault and secondary victimization of female veterans: help-seeking experiences with military and civilian social systems. Psychol Women Q. 2005;29(1):97-106.

25. Friedman LS, Samet $\mathbf{J H}$, Roberts MS, Hudlin $\mathbf{M}$, Hans P. Inquiry about victimization experiences: a survey of patient preferences and physician practices. Arch Intern Med. 1992;152(6):1186-90.

26. McCauley J, Yurk RA, Jenckes MW, Ford DE. Inside "Pandora's box": abused women's experiences with clinicians and health services. J Gen Intern Med. 1998;13(8):549-55.

27. Hamilton AB, Poza I, Hines V, Washington DL. Barriers to psychosocial services among homeless women veterans. J Soc Work Pract Addict. 2012;12(1):52-68.

28. Smelson DA, Sawh L, Kane V, Kuhn J, Ziedonis D. The MISSION-VET Treatment Manual: United States Department of Veterans Affairs, Office of Research and Development, Health Services Research and Development and The National Center on Homelessness Among Veterans; 2011. 